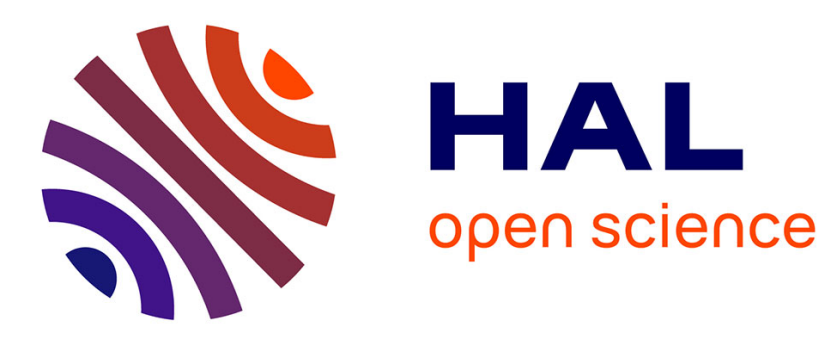

\title{
Intestinal steroidogenesis
}

Guillaume Bouguen, Laurent Dubuquoy, Pierre Desreumaux, Thomas

Brunner, Benjamin Bertin

\section{To cite this version:}

Guillaume Bouguen, Laurent Dubuquoy, Pierre Desreumaux, Thomas Brunner, Benjamin Bertin. Intestinal steroidogenesis. Steroids, 2015, 103, pp.64-71. 10.1016/j.steroids.2014.12.022 . hal-01118231

\section{HAL Id: hal-01118231 \\ https://hal-univ-rennes1.archives-ouvertes.fr/hal-01118231}

Submitted on 18 Feb 2015

HAL is a multi-disciplinary open access archive for the deposit and dissemination of scientific research documents, whether they are published or not. The documents may come from teaching and research institutions in France or abroad, or from public or private research centers.
L'archive ouverte pluridisciplinaire HAL, est destinée au dépôt et à la diffusion de documents scientifiques de niveau recherche, publiés ou non, émanant des établissements d'enseignement et de recherche français ou étrangers, des laboratoires publics ou privés. 


\section{Intestinal steroidogenesis}

Guillaume Bouguen ${ }^{\mathrm{a}, \mathrm{b}}$, Laurent Dubuquoy ${ }^{\mathrm{c}, \mathrm{d}}$, Pierre Desreumaux ${ }^{\mathrm{c}, \mathrm{d}, \mathrm{e}}$, Thomas Brunner ${ }^{\mathrm{f}}$, Benjamin Bertin ${ }^{\mathrm{c}, \mathrm{d}, \mathrm{g}}$

${ }^{\text {a }}$ Service des Maladies de l'Appareil digestif, CHU Pontchaillou, Rennes, France

${ }^{\mathrm{b}}$ UMR991, Liver Metabolism and Cancer, France; Université de Rennes 1, France ${ }^{c}$ Université de Lille, F-59000 Lille, France

${ }^{\mathrm{d}}$ Inserm U995, F-59045 Lille, France

${ }^{\text {e }}$ CHU Lille, Service des Maladies de l'Appareil Digestif et de la Nutrition, Hôpital Claude Huriez, F-59037 Lille, France

${ }^{\mathrm{f}}$ Biochemical Pharmacology, Department of Biology, University of Konstanz, Germany

${ }^{g}$ Faculté des Sciences Pharmaceutiques et Biologiques, F-59006 Lille, France

\section{Correspondence to}

Benjamin Bertin, PhD., Inserm U995, Faculté de médecine, pôle recherche -4 ème étage, 1 place de Verdun, 59045 Lille cedex, France.

Phone +33 320974208 / Fax +33 320974232 .

Email address: benjamin.bertin-2@univ-lille2.fr 


\section{ABSTRACT (234/250words):}

Steroids are fundamental hormones that control a wide variety of physiological processes such as metabolism, immune functions, and sexual characteristics. Historically, steroid synthesis was considered a function restricted to the adrenals and the gonads. In the past 20 years, a significant number of studies have demonstrated that steroids could also be synthesized or metabolized by other organs. According to these studies, the intestine appears to be a major source of de novo produced glucocorticoids as well as a tissue capable of producing and metabolizing sex steroids. This finding is based on the detection of steroidogenic enzyme expression as well as the presence of bioactive steroids in both the rodent and human gut. Within the intestinal mucosa, the intestinal epithelial cell layer is one of the main cellular sources of steroids. Glucocorticoid synthesis regulation in the intestinal epithelial cells is unique in that it does not involve the classical positive regulator steroidogenic factor-1 (SF-1) but a closely related homolog, namely the liver receptor homolog-1 (LRH-1). This local production of immunoregulatory glucocorticoids contributes to intestinal homeostasis and has been linked to pathophysiology of inflammatory bowel diseases. Intestinal epithelial cells also possess the ability to metabolize sex steroids, notably estrogen; this mechanism may impact colorectal cancer development. In this review, we contextualize and discuss what is known about intestinal steroidogenesis and regulation as well as the key role these functions play both in physiological and pathological conditions.

\section{Keywords (6):}

Intestinal steroidogenesis; glucocorticoids; intestinal epithelial cells;

Liver receptor homolog-1; inflammatory bowel diseases; colorectal cancer 


\section{Introduction}

In vertebrates, the mucosal surfaces provide a barrier against invading pathogenic microorganisms but represent also an essential interface exchange between the host and its environment [1]. With a surface of broadly $300 \mathrm{~m}^{2}$ in adults, the intestinal mucosa is the biggest mucosal surface in humans. The gastrointestinal tract is constantly colonized by a huge number of microorganisms (approximately 100 trillion), mostly bacteria, but also viruses and fungi, which are collectively referred to as the microbiota [2]. This colonization leads to a complex mutualistic relationship between the host and the microbiota in which each partner contributes positively to various physiological processes of the other one. For example, the microbiota digests and ferments carbohydrates that provide nutrients to the host cell, produces essential vitamins, contributes to the development of the gut immune system, and protects the host from potential pathogens. In turn, the host regulates microbial ecology by providing nutrients and ecological niches. It also controls microbial density trough the synthesis of antimicrobial peptides and immunoglobulins. This dialog is required to maintain what is commonly called intestinal homeostasis. The disruption of this homeostasis may lead to the development of pathologies such as inflammatory bowel diseases [3, 4].

A fundamental actor in the maintenance of the gut immune homeostasis are the intestinal epithelial cells (IECs) [5, 6]. IECs, located in the intestinal mucosa, provide a physical and biochemical barrier that separates microbiota and immune cells. In addition, interactions of IECs with the microbiota or with pathogens result in anti-microbial and immunoregulatory responses trough the production of numerous molecules [5, 7-9]. One immunoregulatory molecule produced locally by IECs is represented by glucocorticoids (GCs; i.e. cortisol in humans and corticosterone in rodents).

Historically, corticosteroid (glucocorticoids and mineralocorticoids) synthesis only occurred in the adrenal cortex. A significant number of studies have now challenged this view by 
demonstrating that organs such as the thymus [10-12], the skin [13], the brain [14-16], the intestine [17-19], and the lung [20] are capable of producing gluco- or mineralocorticoids.

This review aims to present evidence of local steroid synthesis, particularly that of GCs in the intestine, as well as the key factors involved in the regulation of this production. We discuss the known and potential roles of GCs in the regulation of intestinal homeostasis and then review the data showing that IECs, aside from their ability to produce GCs, are also involved in the metabolism of other steroids (notably sex steroids).

\section{Intestinal Glucocorticoids}

\subsection{Evidence of intestinal GC production}

The steroidogenic ability of the gut was first suggested in the beginning of the 90 's after looking for the expression and activity of the CYP17 (P450c17) enzyme along the gastrointestinal tract of adult rats (see Figure 1 for a schematic representation of the cortisol and sex steroids synthesis pathway). When Dalla Valle et al. assessed the ex vivo metabolism of [4-14C]pregnenolone in various organs, they found that the duodenum and the colon were able to produce high amounts of dehydroepiandrosterone (DHEA), attesting the presence of 17 $\alpha$-hydroxylase and C 17,20-lyase activities in the intestine [21, 22]. While rodents are corticosterone-secreting animals, due to the lack of expression of CYP17 in the adrenal, CYP17 expression in peripheral tissues (notably in the intestine) could lead to the synthesis of local cortisol in rats or mice. However, an early study failed to identify GCs (corticosterone or cortisol) in the small intestine of rats by thin layer chromatography [23]. Moreover, the hypothesis of locally produced cortisol in rodents has never been tested and only corticosterone has been investigated.

In the same period of time, the identification of the transcripts encoding both CYP11A1 (cholesterol side-chain cleavage cytochrome P450; P450scc) and 3ßHSD (3 beta- 
hydroxysteroid dehydrogenase) in the primitive gut of the mouse embryo suggested the ability of the gut to synthesize steroids de novo [24]. The expression of $11 \beta$ HSD2 (11 betahydroxysteroid dehydrogenase 2), which converts active GCs to inactive metabolites, was also detected in the intestine of rodents and humans [25, 26]. Subsequent studies demonstrated steroidogenic enzyme expression as well as intestinal steroid metabolism in various species such as frog [27], fish [28], mouse [17], and human [18, 19, 29]. Most of the comprehensive studies on intestinal steroidogenesis have been undertaken using mouse models. Cima et al. first measured (by radioimmunoassay) the de novo synthesis of corticosterone in murine small intestinal tissue fragments cultured ex vivo [17]. This production was highly stimulated in response to immune activation of $\mathrm{T}$ lymphocytes. Corticosterone synthesis was proven to be in situ, since GC release from tissue was blocked

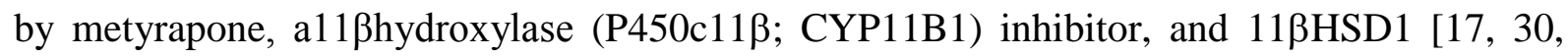

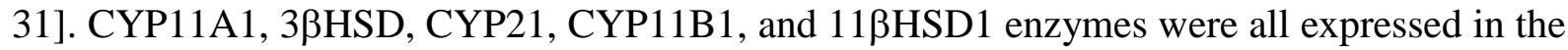
murine small and large intestinal mucosa, but some of them were only detected after immune stimulation [17]. The cellular source of steroidogenic enzymes and GCs was shown to be the IECs located in the crypt region of the small intestine [17]. Further study demonstrated that the expression patterns of mRNA encoding CYP11A1 and CP11B1 were linked to cell cycle. This restricts the main intestinal GC source to the proliferative cells of the intestinal crypts [32].

Initial work by Cima et al. suggested that GC synthesis could also occur in the human intestine, although results were not shown [17]. Earlier observations suggested intestinal steroid metabolism in humans following the detection of $11 \beta \mathrm{HSD}$ and 17 beta-hydroxysteroid dehydrogenase (17ßHSD) enzymes in the colon and along the gastrointestinal tract [26, 33]. More recently, CYP11A1, CYP17 and CYP11B1 and a production of cortisol were observed 
in colorectal cancer cell lines (Caco-2, HT-29) as well as in primary human intestinal tissue and colorectal tumors [18]. Caco-2 cells were also found to constitutionally express 3ßHSD1 and 2 [19], as well as the cholesterol transporter StAR, CYP21 and 11ßHSD1 (B. Bertin, unpublished data). In human tissue, CYP11A1 and CYP11B1 were detected in colonic biopsies suggesting that in physiological state the human mucosa is able to produce GC [29]. We recently confirmed and detailed this finding by showing expression of steroidogenic

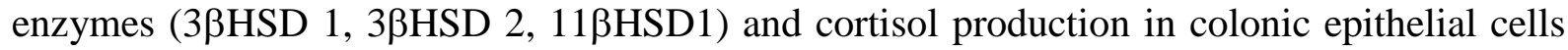
isolated from human surgical specimens [19].

\subsection{Regulation of GC production: from adrenal to the intestine}

In the adrenal, the regulation of cortisol production is well characterized and is the result of a complex interaction between three endocrine glands (hypothalamus, pituitary, and adrenal; HPA), which constitute the HPA axis [34]. Hypothalamic hormones (corticotropin-releasing hormone and vasopressin) induce peptidic adrenocorticotropic hormone (ACTH) secretion in the anterior pituitary, which regulates the synthesis and release of cortisol from the adrenal cortex [34]. ACTH acts on the adrenal steroidogenesis through the stimulation of cholesterol transporter expression and that of the steroidogenic enzymes [35]. The protein SF-1 (steroidogenic factor-1) is one of the key regulators in the expression of these steroidogenic factors in the adrenals. SF-1 belongs to the superfamily of nuclear receptors, which are mainly ligand-dependent transcription factors. SF-1 binds to the promoter and induces the expression of StAR, CYP 450 steroid hydroxylases, $\beta$-hydroxysteroid dehydrogenases as well as melanocortine-2 receptor (MC2R), the receptor for ACTH (reviewed in [36]). The phenotype of adrenocortical (and gonadal) insufficiency in SF-1 knockout mice clearly established this transcription factor as pivotal in the development and physiology of steroidogenic tissues [37, 38]. However, SF-1 is not expressed in the intestinal mucosa $[39,40]$. SF-1 belongs to the 
nuclear receptor subfamily 5, group A, along with its close homolog LRH-1 (liver receptor homolog-1), which is highly expressed in intestinal crypt cells [41], suggesting LRH-1's potential role in the regulation of intestinal steroidogenesis. Indeed, this was first demonstrated in vitro by Mueller and colleagues who showed that LRH-1 induces the CYP11A1 and CYP11B1 expression as well as corticosterone production in the murine intestinal epithelial cell line [40, 42]. In human colon cancer cell lines, the down regulation of LRH-1 by small interfering RNA leads to the reduction of steroidogenic enzyme expression and cortisol synthesis $[18,19]$. In normal human colonic epithelial cells, the expression level of the mRNA encoding LRH-1 strongly correlates with the expression levels of 3ßHSD and $11 \beta$ HSD [19], suggesting that LRH-1 regulates intestinal GC synthesis under physiological state. In vivo, LRH-1 haploinsufficiency in mice confirmed the critical role of LRH-1 in controlling intestinal corticosterone production. Upon activation of T lymphocytes, CYP11A1 and CYP11B1 mRNA levels and corticosterone release were reduced in the intestine of heterozygous LRH-1 ${ }^{+/-}$mice $[42,43]$.

The differential regulation of glucocorticoid synthesis in adrenal and intestinal cells is also illustrated by the observation that $\mathrm{ACTH}$ administration was able to trigger the release of corticosterone from the adrenal but not from the intestine [40]. ACTH mainly mediates its effect through the stimulation of adenylate cyclase leading to an increase of intracellular cyclic adenosine monophosphate (cAMP) level and subsequent protein kinase A activation. Thus, it was observed that increasing intracellular cAMP level in the adrenocortical tumor cell line Y1 induces the expression of CYP11A1 and CYP11B1, while the opposite effect was obtained in the murine intestinal epithelial cell line $\mathrm{mIC}_{\mathrm{c} 12}$ [40]. Conversely, it was shown that phorbolester-dependent protein kinase $\mathrm{C}$ activation was involved in the control of the steroidogenic enzyme expression and GC production in $\mathrm{mIC}_{\mathrm{c} 12}$ cells but not in $\mathrm{Y} 1$ cells [40]. However, LRH-1 mRNA level was slightly modified by cAMP and phorbolester in $\mathrm{mIC}_{\mathrm{c} 12}$. 
Recently Lee and colleagues observed in Hela cell lines the ability of phorbolester to stimulate the phosphorylation of LRH-1 in an ERK1/2-dependent manner [44]. Therefore, rather than a modification of LRH-1 expression, different phosphorylation states of LRH-1 may explain the antagonistic effect of cAMP and phorbolester observed in intestinal epithelial cells [40]. The underlying reasons of the discrepancy between adrenal and intestinal cells during the regulation of cortisol synthesis remain currently unknown and the control of intestinal steroidogenesis by one or several hormonal signals needs to be characterized.

To date, only the induction of strong immune responses has been found to induce intestinal steroidogenesis. Pioneering works have demonstrated that de novo synthesis of corticosterone from small intestinal tissue fragments was highly stimulated in response to immune activation of T lymphocytes [17]. Using lipopolysaccharide (LPS) injection in mice, subsequent studies investigated whether activation of the innate immune system could also induce intestinal steroidogenesis. LPS was able to induce intestinal CYP11A and CYP11B1 expression level and intestinal corticosterone release in $\mathrm{RAG}^{-/-}$mice (which lack $\mathrm{T}$ and $\mathrm{B}$ lymphocytes), suggesting that intestinal GC synthesis induction also occurs independently of the activation of the adaptive immune system [43]. The authors showed that the cells, which contribute to this LPS-induced intestinal steroidogenesis, were macrophages [43].

Finally, the pro-inflammatory cytokine tumor necrosis factor (TNF) was clearly demonstrated to be the common mediator that regulates intestinal GC production in response to the activation of both the innate and adaptative immune system [43]. Following immune stimulation by LPS or activation of T cells, intestinal GC synthesis was compromised both in mice lacking TNF cytokine or TNF receptor expression. The involvement of TNF was later confirmed but the precise role of this cytokine needs further clarifications since opposite effects on gut steroidogenesis were found $[45,46]$. One might argue that the differential involvement of LRH-1 according to the immune response may explain such discrepancies. In 
wild type mice, both activated T cells and LPS were able to induce CYP11B1 expression and corticosterone production in a TNF-dependent manner, but only the $\mathrm{T}$ cell-dependent induction of intestinal steroidogenesis was compromized in LRH-1 haplodeficient animals $\left(\mathrm{LRH}_{-1}{ }^{+/}\right)$, which suggest that LPS drives intestinal GC production independently of LRH-1 [43]. By contrast, Huang et al suggested that TNF-dependent pro-inflammatory signals mediated by NF-kB and JNK suppressed CYP11A1 and CYP11B1 expression by inhibiting LRH-1 transcriptional activity under chronic inflammatory conditions [46]. In summary, the understanding of the regulatory mechanisms of GC synthesis in the gut is just at the beginning, and additional mechanisms involved in the regulation of intestinal steroidogenesis remain to be discovered.

\subsection{Function and roles of intestinal GCs}

\subsubsection{Maturation and maintenance of the intestinal epithelial barrier.}

GC-mediated effects on the maturation of the small intestine are well recognized both in rodents and humans [47]. For instance, adrenalectomy in rats during the weaning period impairs the morphological development of the small intestine [48], while injection of cortisone or hydrocortisone to suckling rats increases the expression and activity of many small intestinal maturation markers [49-51]. The development of a human intestinal xenograft model demonstrated the responsiveness of the human small intestine to cortisone during the maturation period $[52,53]$. More recently, in vitro studies demonstrated the role of GCs in the maintenance of intestinal epithelial barrier integrity [54]. Boivin et al. used a human intestinal epithelial monolayer model consisting of filter-grown Caco-2 cells to investigate the role of GCs on intestinal barrier function. By measuring transepithelial electric resistance (TEER) and paracellular permeability, they showed that synthetic GCs (prednisolone and dexamethasone) had a protective effect against the TNF-dependent increase of intestinal 
permeability [54]. In vitro, a positive effect of dexamethasone on epithelial barrier function was subsequently found independent of the presence of any immunological stimulus [55].The overall in vitro response of human intestinal epithelial cells to GCs was also studied using microarray analysis. This work showed that hydrocortisone differentially regulates the expression levels of protein encoding genes and enterocyte markers involved in polarization and tight junction formation [56]. Altogether, these studies underlined that both endogenous (adrenal-derived) and exogenous GCs play a role during the functional maturation of the gut and the maintenance of intestinal epithelial barrier function. However, during these processes the effective contributions of GCs produced locally by the intestine remain to be established. As compared to the adrenal, the amount of GCs synthesized by IECs under steady state conditions is rather low, and to date there is no experimental evidence of the impact of intestinal GCs on intestinal barrier maturation and/or maintenance. It was previously reported that the specific deletion of LRH-1 in mouse IECs disrupted intestinal steroidogenesis and rendered the conditional knockout animals more susceptible to experimental colitis ([29], see paragraph 4.1). Although a change of intestinal permeability due to the LRH-1-dependent decrease of intestinal GC could explain this phenotype, this hypothesis remains to be tested. Using a short hairpin RNA strategy, we recently created a stable Caco-2 cell line in which the expression of LRH-1 was reduced by $80 \%$ compared to a control cell line [19]. This downregulation of LRH-1 resulted in a reduction of cortisol synthesis and release. However, preliminary experiments did not observed any change of the TEER of this stable cell line up to 21 days when it was differentiated and grown as a monolayer on filters, suggesting that intestinal-derived cortisol may not participate in the development of intestinal barrier (author's unpublished data). Further experiments are needed to investigate the potential role of intestinal GCs on gut epithelial differentiation and barrier function, e.g. the measurement of 
intestinal permeability of LRH-1-deficient mice under steady-state and inflammatory conditions.

\subsubsection{Impact on innate and adaptative immune responses.}

Consistent with the general immunoregulatory properties of GC [57, 58], as well as the induction of intestinal steroidogenesis following immune activation, it is likely that local GC release is involved in the regulation of intestinal immune responses. In order to specifically appreciate the role of GCs released by extra-adrenal sources (such as the intestine), Cima and colleagues removed adrenal glands, and challenged these mice with various $\mathrm{T}$ cell-dependent immunological stresses [17]. Adrenalectomized animals were notably infected with lymphocytic choriomeningitis virus (LCMV) (which triggers a robust cytotoxic T lymphocyte response) in the presence or absence of the GC synthesis inhibitor metyrapone. Then, the virus-specific $\mathrm{T}$ cell activation in the intestine was assessed by monitoring membrane markers expression and cytokine production. LCMV-infected and metyrapone-treated adrenalectomized mice displayed a higher $\mathrm{T}$ cell activation compared to LCMV-infected animals only, indicating that de novo synthesized extra-adrenal corticosterone inhibited the $\mathrm{T}$ cell response. Although this work did not formally demonstrate the intestine as the only source of GCs, results obtained by Cima et al. strongly suggested its impact. [42]. Regarding specifically the gut, heterozygous $\mathrm{LRH}-1^{+/-}$mice, which present a decreased expression of steroidogenic enzymes and corticosterone release were more susceptible to experimental colitis induced by either 2,4,6-trinitrobenzene sulfonic acid (TNBS) or dextran sodium sulfate (DSS) [29]. However LRH-1 expression was reduced in all cell types of rodents, making it difficult to exclude the contribution of GCs produced by other cells, such as immune cells [59]. But the immunoregulatory role of GCs synthesized by the IECs was further supported by more specific experiments in the same study when enterocyte-specific LRH-1-deficient mice 
produced less colonic corticosterone after TNBS treatment and displayed more severe inflammatory lesions in the large intestine [29] Beside the immunoregulatory properties of GCs, other mechanisms such as the maintenance of the intestinal barrier and/or the recovery of the epithelial layer by promoting progenitor cell proliferation through LRH-1 might also regulate colitis. However, chemically-induced models of colitis imperfectly reproduced the cellular and molecular aspects of the physiopathology of inflammatory bowel diseases (IBD), these results led also to the assessment of the expression of LRH-1 and intestinal GCs synthesis in patients suffering from IBD (see paragraph 4.1).

Apart from the characterization of $\mathrm{T}$ lymphocytes as targets of intestinal GCs, no other cellular target has been described yet. It has recently been demonstrated that a fundamental dialog between IEC and dendritic cells (DCs) takes place within the intestinal mucosa to maintain gut homeostasis. DCs are professional antigen presenting cells (APC) viewed as one of the gate keepers of the immune system forming a bridge between the innate and adaptive immune responses. Recent studies demonstrated that IECs educate intestinal DCs to suppress inflammation and promote tolerance and gut immune homeostasis [7, 9, 60]. Several immunoregulatory molecules, such as TGF- $\beta$ (transforming growth factor- $\beta$ ), retinoic-acid or TSLP (thymic stromal lymphopoietin), produced by IECs are crucially involved in this tolerogenic process [5]. Therefore, it is tempting to speculate that immunoregulatory GCs released by IECs might have a similar role in promoting the development of DCs (or others APC) with tolerogenic properties. All the same, this hypothesis remains to be tested.

\subsubsection{Other properties of intestinal GCs}

Next to GR-mediated effects regulation of GC-sensitive genes, there is also accumulating evidence for non-genomic effects of GCs. For example, GCs have been reported to mediate 
certain biological effects via interaction with cellular membranes, via cytosolic GR and via membrane-bound GC receptors [61].

Some gut-specific properties have been allocated to this intestinal steroidogenesis. Cortisol released by IECs has been recently demonstrated to be involved in the control of the intestinal expression of PPAR $\gamma$ (peroxisome proliferator activated receptor gamma), a key factor in the regulation of gut homeostasis. The colon is a major PPAR $\gamma$-expressing tissue with the colonic epithelial cells as the main source of expression [62, 63]. PPAR $\gamma$ belongs to the nuclear receptor superfamily and has been shown to be a critical regulator of inflammatory responses [63-67]. This property involves typical positive gene regulation by binding of the PPAR $\gamma-$ RXR (RXR, retinoid X receptor) heterodimer to the PPAR-response element (PPRE) located in the promoter of target genes. In addition a direct interference with transcription factors involved in the inflammatory response, such as NF- $\mathrm{B}$ (nuclear factor kappa-light-chainenhancer of activated B cells), AP-1 (activating protein-1) and ROR $\gamma \mathrm{t}$ (retinoic acid receptorrelated orphan receptor gamma t), has been demonstrated in a mechanism often referred to as “transrepression” [67]. In a stable Caco2-cell line with effective LRH-1 knockdown cortisol production and release, as well as PPAR $\gamma$ mRNA and protein expression were drastically reduced [19]. This inhibition of PPAR $\gamma$ expression was reversed to the normal levels following the treatment of the cell line by exogenous GCs. As a control, knockdown of PPAR $\gamma$ by the same strategy did not result in a decrease of cortisol release or LRH-1 expression [19]. These experiments pointed out a key role of intestinal cortisol synthesis in the regulation of intestinal PPAR $\gamma$ and PPAR $\gamma$-mediated gut homeostasis.

Environmental stresses induce adaptive response of IECs with high secretory activity. The endoplasmic reticulum (ER) folds and matures most secreted and transmembrane proteins. The imbalance between protein load observed in stress situation and folding ability of the ER 
is defined as ER stress, and the coordinated response triggered is known as UPR (Unfold Protein Response) to ensure homeostatic cell control $[68,69]$. UPR induces several pathways that lead to a reduced protein load that enters the ER, to increase the ability of the ER to handle unfolded proteins and in some circumstances to trigger cell death [68]. In the intestine disregulation of normal ER responses are particularly sensitive since dysfunction of UPR leads to spontaneous colitis in rodents lacking the transcription factor XBP1 (X-box-binding protein-1), involved in protein load $[70,71]$. In Winnie mice with increased intestinal ER stress caused by a missense mutation of the Muc2 mucin gene, GCs suppress ER stress and activation of the UPR in a glucocorticoid receptor-dependent manner [72]. GCs promote correct folding of secreted proteins and facilitate the enhanced removal of misfolded proteins from the ER through up-regulation of genes encoding chaperones and elements of ERassociated degradation (ERAD) [72]. These results suggest that epithelial steroidogenesis may also influence gut homeostasis by modulating ER responses in response to exogenous and endogenous stresses.

\section{Metabolism and function of other steroids in the gut}

The steroidogenesis involves not only the production of GCs but also other steroids such as mineralocorticoids and sex steroids (androgens and estrogens). In parallel to the description of gut production of GCs, the ability of IECs to metabolize sex steroids was assessed. From a chemical point of view, few enzymatic steps are required to obtain androgens and estrogens from common precursors of GCs involving the 3 enzymes $17 \alpha$-hydroxylase/17,20-lyase (P450c17), and the17ß-hydroxysteroid dehydrogenase (17ßHSD). For estrogens there is an additional enzyme, the aromatase (P450aro) (Figure 1). Early in vitro and in vivo studies observed the expression of enzymes involved in estrogen metabolism in colorectal cancer cell lines and normal gut mucosa $[33,73-76]$. Evidence of estrogen production by the IECs in 
healthy humans was then assessed leading to the observation of higher mucosal production of estrone as compared to estradiol [77].

An important aspect of estrogens is their synthesis in diverse tissues. This may lead to variable exposition of IECs by estrogens, depending on sex or diet, in addition to their own production in the intestinal mucosa. The 17 $\beta$-hydroxysteroid dehydrogenase (17 $\beta$-HSD) family acts in key steps of the synthesis of sex steroid hormones, mainly of active estrogens and androgens [78]. Several isoforms of the 17 $\beta$-HSD enzyme with diverse enzymatic activities have been characterized in humans and were thoroughly investigated in human colonic mucosa, which mainly express isoform 2 and 4 [75]. These isoforms catalyze the oxidative transformation of estradiol and testosterone to estrone and androstenedione, respectively, which is thus considered to play an important role in the peripheral inactivation of estrogen and androgen [33, 74, 78, 79].

Similarly to GCs, estrogens metabolism (mainly estradiol) seems to occur predominantly in the intestinal crypts of the colon and may thereby exert a significant effect on colonic epithelial cell growth $[33,80]$. Of interest in this regard is the observation that ovariectomy appears to induce colonic crypt atrophy [81]. Estrogen receptor- $\beta$ (ER- $\beta$ ) is highly expressed in gut epithelial cells $[82,83]$ and ER- $\beta$ signaling is involved in cellular homeostasis and maintenance of the colonic epithelial barrier function [84, 85]. Disruption of ER- $\beta$ expression in ER- $\beta$ KO mice was notably associated with an increase in epithelial cell proliferation, and a decrease of apoptosis and the expression of cellular adhesion molecules [84].

\section{Involvement of intestinal steroidogenesis in pathological disorders}

\subsection{Inflammatory Bowel Diseases}


Inflammatory Bowel Diseases (IBDs), namely ulcerative colitis (UC) and Crohn's disease (CD) are chronic, complex, relapsing immune-mediated disorders of the gastrointestinal tract of unknown etiology. Emerging evidence suggests that disease development involves a deregulated immune response to the gut microbiome in genetically susceptible individuals, triggered by environmental factors [86-89]. The expression of CYP11A1, CYP11B1 and LRH-1 were first shown to be decreased in inflamed colon biopsies of CD and UC patients compared to non-inflamed biopsies of IBD patients and control subjects [29]. These observations strongly suggest that impaired production of intestinal GCs might participate in the pathogenesis of IBD. This notion was recently newly strengthened by our recent report [19]. While UC and CD share some clinical manifestations, they are distinct pathophysiological diseases. For instance, in contrast to the characteristic transmural lesions that can affect all the intestinal layers in CD patients, inflammation during UC is restricted to colonic mucosa and sub-mucosa. Moreover, recent studies suggest that IEC dysfunction may critically contribute to the pathogenesis of UC $[90,91]$. Our recent work demonstrated that colonic epithelial cells (CEC) isolated from surgical specimens of UC patients have a decreased expression of LRH-1 and some steroidogenic enzymes that ultimately result in a cortisol production deficiency. This impairment of epithelial steroidogenesis was correlated with a decrease of the anti-inflammatory factor PPAR $\gamma$ [19]. This study demonstrates complete steroidogenesis and cortisol production in normal human CECs, highlighting a new component of intestinal epithelial barrier regulation. In addition, these results enlarge the GC mechanism of action by suggesting a new anti-inflammatory role of corticosteroids via the induction of PPAR $\gamma$ expression in IECs. These findings also support the notion that intestinal production of GCs is a key element in the control of intestinal homeostasis and that the defective synthesis of cortisol by CECs may actively contribute to the pathogenesis of UC. 
During IBD two other circumstances may involve intestinal steroidogenesis. We discussed above the possible impact of GCs on ER stress. Induction of ER stress in intestinal epithelium through tissue (and cell type)-specific disruption of XBP1 was shown to result in spontaneous enteritis due to inability of XBP1-deficient IECs to properly generate antimicrobial activity and respond appropriately to inflammatory signals in the local milieu [70]. This concept was translated to patients with IBD, who are more likely to develop both CD and UC when bearing single nucleotide polymorphisms within the XBP1 gene locus [70]. The steroidogenesis state in patients with CD is not yet known. Since GCs are able to relieve the ER stress [72], UPR are more likely to be impaired in UC patients with defective IEC synthesis of cortisol.

Another side of steroidogenesis implies sex hormones, particularly estrogens. In two large prospective cohorts of women a significant association between oral contraceptive use and risk of $\mathrm{CD}$ were also associated with a modest, but non-significant increase in risk of UC [92]. Conversely postmenopausal hormone use was associated with an increased risk of UC but not CD. As discussed previously, estrogen signaling is involved in the colonic barrier function $[84,85]$. Decreased estrogen receptor $\beta$ mRNA levels were observed in colonic biopsies from IBD patients as well as in IL-10 deficient mice (a model of IBD), which correlated with an increase in epithelial permeability [85]. These findings indicate a potential impact of sex hormones, in particular estrogens, on IBD development. However, to our knowledge no study has thus far assessed estrogen synthesis in the intestinal mucosa of IBD patients

\subsection{Colorectal cancer (CRC)}

Epidemiological and observational studies pointed out a correlation of exogenous and endogenous estrogens in the development of colorectal cancer (CRC) with a possible increased risk in women with higher circulating endogenous estrogen concentrations [93]. 
Estrogens may induce colorectal cancer cell apoptosis by binding to estrogen receptor $\beta,[73$, 94]. A2-2.4-fold increased of estrogen (mainly estrone rather than estradiol) were observed in colon carcinoma tissues [77]. This may be related to overexpression of enzymes involved in steroid synthesis pathway, such as sulfatase and mainly 17HSD isoform 2 [77, 79]. The $17 \beta \mathrm{HSD} 2$ catalyzes the oxidative transformation of estradiol to estrone [74]. Both the level of estradiol and 17ßHSD have been associated with CRC and disease progression irrespective of sex. Since IECs are a source of estrogen, the control of epithelial steroidogenesis could be useful to control CRC onset and progression.

Another hypothetical involvement of IEC steroidogenesis may be via PPAR $\gamma$. Beside the antiinflammatory properties of $\operatorname{PPAR} \gamma$ this nuclear receptor regulates cell proliferation, differentiation and is able to induce apoptosis [95]. Activation of PPAR $\gamma$ by a synthetic ligand (mesalasine) has been shown to inhibit cancer growth by decreasing cell proliferation and increase cell apoptosis [96]. Since a decrease of PPAR $\gamma$ expression has been observed in some

patients bearing CRC [97], a decrease in local GCs production in these patients may be involved, but no data are presently available. On the other hand, it has been demonstrated that CRC cell lines and primary tumor samples produce and release cortisol that can potentially modulate $\mathrm{T}$ cell-dependent anti-tumoral immune response, thereby contributing to tumor immune escape [18].

\section{Conclusion}

Steroid metabolism has been demonstrated and confirmed in the intestine. IECs are able to de novo synthesize and release GCs that regulate the gut immune response. The defective synthesis of cortisol identified in the colonic epithelial cells of UC patients strengthens the idea that intestinal GCs contribute to intestinal homeostasis. In addition, perturbations of 
estrogen metabolism are also evident in CRC cells, strongly suggesting that steroid metabolism is an important process during IEC homeostasis.

Whereas in classical steroidogenic organs (adrenals and gonads), the regulation of steroid production is well characterized, a lot of work remains to be done in order to identify the mechanisms controlling intestinal steroidogenesis. For instance, the recent identification of microbiota as a potential regulator of corticosterone production by the small intestine in mice [98] may pave the way to design new studies that aim to more thoroughly characterize the production of GCs in the gut. Given the involvement of steroids produced by the gut in pathological conditions such as CRC and IBD, therapeutic strategies targeting intestinal steroidogenesis might represent interesting new approaches for the treatment of these chronic diseases. 


\section{Acknowledgement}

Research from the Pr. Desreumaux's lab on this subject was supported by research grants from Ferring, the Association François Aupetit and BREMICI (Shering-Plough). Research from the Pr. Brunner's lab on this subject was supported by grants from the German Research Foundation. English proofreading services were provided by Rachel Tipton.

\section{Conflict of interest}

GB received lecture fees from Ferring, MSD pharma, Abbvie.

PD has the following conflicts of interest for consulting fees, lecture fees or grant supports in the field of PPAR with Giuliani SpA, Milano, Italy, Procter and Gamble, London, UK, Shire Pharmaceuticals, USA and Lesaffre, Marcq en Baroeul, France.

LD, TB and BB have no conflict of interest to disclose. 


\section{REFERENCES}

[1] Sansonetti PJ. War and peace at mucosal surfaces. Nat Rev Immunol. 2004;4:953-64.

[2] Walter J, Ley R. The human gut microbiome: ecology and recent evolutionary changes. Annu Rev Microbiol. 2011;65:411-29.

[3] Kamada N, Seo SU, Chen GY, Nunez G. Role of the gut microbiota in immunity and inflammatory disease. Nat Rev Immunol. 2013;13:321-35.

[4] Maloy KJ, Powrie F. Intestinal homeostasis and its breakdown in inflammatory bowel disease. Nature. 2011;474:298-306.

[5] Peterson LW, Artis D. Intestinal epithelial cells: regulators of barrier function and immune homeostasis. Nat Rev Immunol. 2014;14:141-53.

[6] Goto Y, Ivanov, II. Intestinal epithelial cells as mediators of the commensal-host immune crosstalk. Immunol Cell Biol. 2013;91:204-14.

[7] Rimoldi M, Chieppa M, Salucci V, Avogadri F, Sonzogni A, Sampietro GM, et al. Intestinal immune homeostasis is regulated by the crosstalk between epithelial cells and dendritic cells. Nat Immunol. 2005;6:507-14.

[8] Iliev ID, Mileti E, Matteoli G, Chieppa M, Rescigno M. Intestinal epithelial cells promote colitis-protective regulatory $\mathrm{T}$-cell differentiation through dendritic cell conditioning. Mucosal Immunol. 2009;2:340-50.

[9] Iliev ID, Spadoni I, Mileti E, Matteoli G, Sonzogni A, Sampietro GM, et al. Human intestinal epithelial cells promote the differentiation of tolerogenic dendritic cells. Gut. 2009;58:1481-9.

[10] Vacchio MS, Papadopoulos V, Ashwell JD. Steroid production in the thymus: implications for thymocyte selection. J Exp Med. 1994;179:1835-46. 
[11] Pazirandeh A, Xue Y, Rafter I, Sjovall J, Jondal M, Okret S. Paracrine glucocorticoid activity produced by mouse thymic epithelial cells. Faseb J. 1999;13:893-901.

[12] Lechner O, Wiegers GJ, Oliveira-Dos-Santos AJ, Dietrich H, Recheis H, Waterman M, et al. Glucocorticoid production in the murine thymus. Eur J Immunol. 2000;30:337-46.

[13] Thiboutot D, Jabara S, McAllister JM, Sivarajah A, Gilliland K, Cong Z, et al. Human skin is a steroidogenic tissue: steroidogenic enzymes and cofactors are expressed in epidermis, normal sebocytes, and an immortalized sebocyte cell line (SEB-1). J Invest Dermatol. 2003;120:905-14.

[14] Gomez-Sanchez CE, Zhou MY, Cozza EN, Morita H, Eddleman FC, Gomez-Sanchez EP. Corticosteroid synthesis in the central nervous system. Endocr Res. 1996;22:463-70.

[15] Croft AP, O'Callaghan MJ, Shaw SG, Connolly G, Jacquot C, Little HJ. Effects of minor laboratory procedures, adrenalectomy, social defeat or acute alcohol on regional brain concentrations of corticosterone. Brain Res. 2008;1238:12-22.

[16] Little HJ, Croft AP, O'Callaghan MJ, Brooks SP, Wang G, Shaw SG. Selective increases in regional brain glucocorticoid: a novel effect of chronic alcohol. Neuroscience. 2008;156:1017-27.

[17] Cima I, Corazza N, Dick B, Fuhrer A, Herren S, Jakob S, et al. Intestinal epithelial cells synthesize glucocorticoids and regulate T cell activation. J Exp Med. 2004;200:1635-46.

[18] Sidler D, Renzulli P, Schnoz C, Berger B, Schneider-Jakob S, Fluck C, et al. Colon cancer cells produce immunoregulatory glucocorticoids. Oncogene. 2011;30:2411-9.

[19] Bouguen G, Langlois A, Djouina M, Branche J, Koriche D, Dewaeles E, et al. Intestinal steroidogenesis controls PPARgamma expression in the colon and is impaired during UC. Gut. Published on line first 2014 july 22 
[20] Hostettler N, Bianchi P, Gennari-Moser C, Kassahn D, Schoonjans K, Corazza N, et al. Local glucocorticoid production in the mouse lung is induced by immune cell stimulation. Allergy. 2012;67:227-34.

[21] Dalla Valle L, Belvedere P, Simontacchi C, Colombo L. Extraglandular hormonal steroidogenesis in aged rats. J Steroid Biochem Mol Biol. 1992;43:1095-8.

[22] Dalla Valle L, Couet J, Labrie Y, Simard J, Belvedere P, Simontacchi C, et al. Occurrence of cytochrome P450c17 mRNA and dehydroepiandrosterone biosynthesis in the rat gastrointestinal tract. Mol Cell Endocrinol. 1995;111:83-92.

[23] Vianello S, Waterman MR, Dalla Valle L, Colombo L. Developmentally regulated expression and activity of 17alpha-hydroxylase/C-17,20-lyase cytochrome $\mathrm{P} 450$ in rat liver. Endocrinology. 1997;138:3166-74.

[24] Keeney DS, Ikeda Y, Waterman MR, Parker KL. Cholesterol side-chain cleavage cytochrome $\mathrm{P} 450$ gene expression in the primitive gut of the mouse embryo does not require steroidogenic factor 1. Mol Endocrinol. 1995;9:1091-8.

[25] Pacha J, Miksik I. Distribution of 11 beta-hydroxysteroid dehydrogenase along the rat intestine. Life Sci. 1994;54:745-9.

[26] Whorwood CB, Ricketts ML, Stewart PM. Epithelial cell localization of type 211 betahydroxysteroid dehydrogenase in rat and human colon. Endocrinology. 1994;135:2533-41.

[27] Belvedere P, Dalla Valle L, Vianello S, Carnevali O, Colombo L. Hormonal steroidogenesis in liver and small intestine of the green frog, Rana esculenta L. Life Sci. 2001;69:2921-30.

[28] Wang Y, Ge W. Cloning of zebrafish ovarian P450c17 (CYP17, 17alpha-hydroxylase/17, 20-lyase) and characterization of its expression in gonadal and extra-gonadal tissues. Gen Comp Endocrinol. 2004;135:241-9. 
[29] Coste A, Dubuquoy L, Barnouin R, Annicotte JS, Magnier B, Notti M, et al. LRH-1mediated glucocorticoid synthesis in enterocytes protects against inflammatory bowel disease. Proc Natl Acad Sci U S A. 2007;104:13098-103.

[30] Dominguez OV, Samuels LT. Mechanism of Inhibition of Adrenal Steroid 11betaHydroxylase by Methopyrapone (Metopirone). Endocrinology. 1963;73:304-9.

[31] Sampath-Kumar R, Yu M, Khalil MW, Yang K. Metyrapone is a competitive inhibitor of 11beta-hydroxysteroid dehydrogenase type 1 reductase. J Steroid Biochem Mol Biol. 1997;62:195-9.

[32] Atanasov AG, Leiser D, Roesselet C, Noti M, Corazza N, Schoonjans K, et al. Cell cycle-dependent regulation of extra-adrenal glucocorticoid synthesis in murine intestinal epithelial cells. Faseb J. 2008;22:4117-25.

[33] Sano T, Hirasawa G, Takeyama J, Darnel AD, Suzuki T, Moriya T, et al. 17 betaHydroxysteroid dehydrogenase type 2 expression and enzyme activity in the human gastrointestinal tract. Clin Sci (Lond). 2001;101:485-91.

[34] Papadimitriou A, Priftis KN. Regulation of the hypothalamic-pituitary-adrenal axis. Neuroimmunomodulation. 2009;16:265-71.

[35] Sewer MB, Waterman MR. Insights into the transcriptional regulation of steroidogenic enzymes and StAR. Rev Endocr Metab Disord. 2001;2:269-74.

[36] Schimmer BP, White PC. Minireview: steroidogenic factor 1: its roles in differentiation, development, and disease. Mol Endocrinol. 2010;24:1322-37.

[37] Luo X, Ikeda Y, Parker KL. A cell-specific nuclear receptor is essential for adrenal and gonadal development and sexual differentiation. Cell. 1994;77:481-90.

[38] Parker KL, Schimmer BP. Steroidogenic factor 1: a key determinant of endocrine development and function. Endocr Rev. 1997;18:361-77. 
[39] Ramayya MS, Zhou J, Kino T, Segars JH, Bondy CA, Chrousos GP. Steroidogenic factor 1 messenger ribonucleic acid expression in steroidogenic and nonsteroidogenic human tissues: Northern blot and in situ hybridization studies. J Clin Endocrinol Metab. 1997;82:1799-806.

[40] Mueller M, Atanasov A, Cima I, Corazza N, Schoonjans K, Brunner T. Differential regulation of glucocorticoid synthesis in murine intestinal epithelial versus adrenocortical cell lines. Endocrinology. 2007;148:1445-53.

[41] Botrugno OA, Fayard E, Annicotte JS, Haby C, Brennan T, Wendling O, et al. Synergy between LRH-1 and beta-catenin induces G1 cyclin-mediated cell proliferation. Mol Cell. 2004;15:499-509.

[42] Mueller M, Cima I, Noti M, Fuhrer A, Jakob S, Dubuquoy L, et al. The nuclear receptor LRH-1 critically regulates extra-adrenal glucocorticoid synthesis in the intestine. J Exp Med. 2006;203:2057-62.

[43] Noti M, Corazza N, Tuffin G, Schoonjans K, Brunner T. Lipopolysaccharide induces intestinal glucocorticoid synthesis in a TNFalpha-dependent manner. Faseb J. 2010;24:13406.

[44] Lee YK, Choi YH, Chua S, Park YJ, Moore DD. Phosphorylation of the hinge domain of the nuclear hormone receptor LRH-1 stimulates transactivation. J Biol Chem. 2006;281:78505.

[45] Noti M, Corazza N, Mueller C, Berger B, Brunner T. TNF suppresses acute intestinal inflammation by inducing local glucocorticoid synthesis. J Exp Med. 2010;207:1057-66.

[46] Huang SC, Lee CT, Chung BC. Tumor necrosis factor suppresses NR5A2 activity and intestinal glucocorticoid synthesis to sustain chronic colitis. Sci Signal. 2014;7:ra20.

[47] Drozdowski L, Thomson AB. Intestinal hormones and growth factors: effects on the small intestine. World J Gastroenterol. 2009;15:385-406. 
[48] Miyata T, Minai Y, Haga M. Impaired growth of small intestinal epithelium by adrenalectomy in weaning rats. Acta Histochem Cytochem. 2008;41:83-8.

[49] Yeh KY, Yeh M, Holt PR. Thyroxine and cortisone cooperate to modulate postnatal intestinal enzyme differentiation in the rat. Am J Physiol. 1991;260:G371-8.

[50] Schaeffer C, Diab-Assef M, Plateroti M, Laurent-Huck F, Reimund JM, Kedinger M, et al. Cytokine gene expression during postnatal small intestinal development: regulation by glucocorticoids. Gut. 2000;47:192-8.

[51] Biol-N'garagba M C, Niepceron E, Mathian B, Louisot P. Glucocorticoid-induced maturation of glycoprotein galactosylation and fucosylation processes in the rat small intestine. J Steroid Biochem Mol Biol. 2003;84:411-22.

[52] Nanthakumar NN, Klopcic CE, Fernandez I, Walker WA. Normal and glucocorticoidinduced development of the human small intestinal xenograft. Am J Physiol Regul Integr Comp Physiol. 2003;285:R162-70.

[53] Nanthakumar NN, Young C, Ko JS, Meng D, Chen J, Buie T, et al. Glucocorticoid responsiveness in developing human intestine: possible role in prevention of necrotizing enterocolitis. Am J Physiol Gastrointest Liver Physiol. 2005;288:G85-92.

[54] Boivin MA, Ye D, Kennedy JC, Al-Sadi R, Shepela C, Ma TY. Mechanism of glucocorticoid regulation of the intestinal tight junction barrier. Am J Physiol Gastrointest Liver Physiol. 2007;292:G590-8.

[55] Fischer A, Gluth M, Weege F, Pape UF, Wiedenmann B, Baumgart DC, et al. Glucocorticoids regulate barrier function and claudin expression in intestinal epithelial cells via MKP-1. Am J Physiol Gastrointest Liver Physiol. 2014;306:G218-28.

[56] Lu L, Li T, Williams G, Petit E, Borowsky M, Walker WA. Hydrocortisone induces changes in gene expression and differentiation in immature human enterocytes. Am J Physiol Gastrointest Liver Physiol. 2011;300:G425-32. 
[57] Rhen T, Cidlowski JA. Antiinflammatory action of glucocorticoids--new mechanisms for old drugs. N Engl J Med. 2005;353:1711-23.

[58] De Bosscher K, Haegeman G. Minireview: latest perspectives on antiinflammatory actions of glucocorticoids. Mol Endocrinol. 2009;23:281-91.

[59] Jia Y, Domenico J, Takeda K, Han J, Wang M, Armstrong M, et al. Steroidogenic enzyme Cyp11a1 regulates Type $2 \mathrm{CD} 8+\mathrm{T}$ cell skewing in allergic lung disease. Proc Natl Acad Sci U S A. 2013;110:8152-7.

[60] Zeuthen LH, Fink LN, Frokiaer H. Epithelial cells prime the immune response to an array of gut-derived commensals towards a tolerogenic phenotype through distinct actions of thymic stromal lymphopoietin and transforming growth factor-beta. Immunology. 2008;123:197-208.

[61] Stahn C, Lowenberg M, Hommes DW, Buttgereit F. Molecular mechanisms of glucocorticoid action and selective glucocorticoid receptor agonists. Mol Cell Endocrinol. 2007;275:71-8.

[62] Fajas L, Auboeuf D, Raspe E, Schoonjans K, Lefebvre AM, Saladin R, et al. The organization, promoter analysis, and expression of the human PPARgamma gene. $\mathrm{J}$ Biol Chem. 1997;272:18779-89.

[63] Dubuquoy L, Rousseaux C, Thuru X, Peyrin-Biroulet L, Romano O, Chavatte P, et al. PPARgamma as a new therapeutic target in inflammatory bowel diseases. Gut. 2006;55:13419.

[64] Ricote M, Li AC, Willson TM, Kelly CJ, Glass CK. The peroxisome proliferatoractivated receptor-gamma is a negative regulator of macrophage activation. Nature. 1998;391:79-82.

[65] Jiang C, Ting AT, Seed B. PPAR-gamma agonists inhibit production of monocyte inflammatory cytokines. Nature. 1998;391:82-6. 
[66] Tontonoz P, Spiegelman BM. Fat and beyond: the diverse biology of PPARgamma. Annu Rev Biochem. 2008;77:289-312.

[67] Glass CK, Saijo K. Nuclear receptor transrepression pathways that regulate inflammation in macrophages and T cells. Nat Rev Immunol. 2010;10:365-76.

[68] Ron D, Walter P. Signal integration in the endoplasmic reticulum unfolded protein response. Nat Rev Mol Cell Biol. 2007;8:519-29.

[69] Todd DJ, Lee AH, Glimcher LH. The endoplasmic reticulum stress response in immunity and autoimmunity. Nat Rev Immunol. 2008;8:663-74.

[70] Kaser A, Lee AH, Franke A, Glickman JN, Zeissig S, Tilg H, et al. XBP1 links ER stress to intestinal inflammation and confers genetic risk for human inflammatory bowel disease. Cell. 2008;134:743-56.

[71] Kaser A, Blumberg RS. Endoplasmic reticulum stress in the intestinal epithelium and inflammatory bowel disease. Semin Immunol. 2009;21:156-63.

[72] Das I, Png CW, Oancea I, Hasnain SZ, Lourie R, Proctor M, et al. Glucocorticoids alleviate intestinal ER stress by enhancing protein folding and degradation of misfolded proteins. J Exp Med. 2013;210:1201-16.

[73] Fiorelli G, Picariello L, Martineti V, Tonelli F, Brandi ML. Estrogen synthesis in human colon cancer epithelial cells. J Steroid Biochem Mol Biol. 1999;71:223-30.

[74] Fiorelli G, Picariello L, Martineti V, Tognarini I, Tonelli F, Brandi ML. Estrogen metabolism in human colorectal cancer cells. J Steroid Biochem Mol Biol. 2002;81:281-9. [75] English MA, Stewart PM, Hewison M. Estrogen metabolism and malignancy: analysis of the expression and function of 17beta-hydroxysteroid dehydrogenases in colonic cancer. Mol Cell Endocrinol. 2001;171:53-60.

[76] Sato R, Suzuki T, Katayose Y, Miura K, Shiiba K, Miki Y, et al. Aromatase in colon carcinoma. Anticancer Res. 2012;32:3069-75. 
[77] Sato R, Suzuki T, Katayose Y, Miura K, Shiiba K, Tateno H, et al. Steroid sulfatase and estrogen sulfotransferase in colon carcinoma: regulators of intratumoral estrogen concentrations and potent prognostic factors. Cancer Res. 2009;69:914-22.

[78] Oduwole OO, Makinen MJ, Isomaa VV, Pulkka A, Jernvall P, Karttunen TJ, et al. 17Beta-hydroxysteroid dehydrogenase type 2: independent prognostic significance and evidence of estrogen protection in female patients with colon cancer. J Steroid Biochem Mol Biol. 2003;87:133-40.

[79] Oduwole OO, Isomaa VV, Nokelainen PA, Stenback F, Vihko PT. Downregulation of estrogen-metabolizing 17 beta-hydroxysteroid dehydrogenase type 2 expression correlates inversely with Ki67 proliferation marker in colon-cancer development. Int J Cancer. 2002;97:1-6.

[80] Narayan S, Rajakumar G, Prouix H, Singh P. Estradiol is trophic for colon cancer in mice: effect on ornithine decarboxylase and c-myc messenger RNA. Gastroenterology. $1992 ; 103: 1823-32$.

[81] Hoff MB, Chang WW, Mak KM. Effect of estrogen on cell proliferation in colonic mucosa of the mouse. Virchows Arch B Cell Pathol Incl Mol Pathol. 1981;35:263-73.

[82] Campbell-Thompson M, Lynch IJ, Bhardwaj B. Expression of estrogen receptor (ER) subtypes and ERbeta isoforms in colon cancer. Cancer Res. 2001;61:632-40.

[83] Konstantinopoulos PA, Kominea A, Vandoros G, Sykiotis GP, Andricopoulos P, Varakis I, et al. Oestrogen receptor beta (ERbeta) is abundantly expressed in normal colonic mucosa, but declines in colon adenocarcinoma paralleling the tumour's dedifferentiation. Eur J Cancer. 2003;39:1251-8.

[84] Wada-Hiraike O, Imamov O, Hiraike H, Hultenby K, Schwend T, Omoto Y, et al. Role of estrogen receptor beta in colonic epithelium. Proc Natl Acad Sci U S A. 2006;103:2959-64. 
[85] Looijer-van Langen M, Hotte N, Dieleman LA, Albert E, Mulder C, Madsen KL. Estrogen receptor-beta signaling modulates epithelial barrier function. Am J Physiol Gastrointest Liver Physiol. 2011;300:G621-6.

[86] Baumgart DC, Carding SR. Inflammatory bowel disease: cause and immunobiology. Lancet. 2007;369:1627-40.

[87] Baumgart DC, Sandborn WJ. Inflammatory bowel disease: clinical aspects and established and evolving therapies. Lancet. 2007;369:1641-57.

[88] Baumgart DC, Sandborn WJ. Crohn's disease. Lancet. 2012;380:1590-605.

[89] Ordas I, Eckmann L, Talamini M, Baumgart DC, Sandborn WJ. Ulcerative colitis. Lancet. 2012;380:1606-19.

[90] Danese S, Fiocchi C. Ulcerative colitis. N Engl J Med. 2011;365:1713-25.

[91] Anderson CA, Boucher G, Lees CW, Franke A, D'Amato M, Taylor KD, et al. Metaanalysis identifies 29 additional ulcerative colitis risk loci, increasing the number of confirmed associations to 47. Nat Genet. 2011;43:246-52.

[92] Khalili H, Higuchi LM, Ananthakrishnan AN, Richter JM, Feskanich D, Fuchs CS, et al. Oral contraceptives, reproductive factors and risk of inflammatory bowel disease. Gut. 2013;62:1153-9.

[93] Foster PA. Oestrogen and colorectal cancer: mechanisms and controversies. Int J Colorectal Dis. 2013;28:737-49.

[94] Wilkins HR, Doucet K, Duke V, Morra A, Johnson N. Estrogen prevents sustained COLO-205 human colon cancer cell growth by inducing apoptosis, decreasing c-myb protein, and decreasing transcription of the anti-apoptotic protein bcl-2. Tumour Biol. 2010;31:16-22. [95] Han S, Roman J. Peroxisome proliferator-activated receptor gamma: a novel target for cancer therapeutics? Anticancer Drugs. 2007;18:237-44. 
[96] Schwab M, Reynders V, Loitsch S, Shastri YM, Steinhilber D, Schroder O, et al. PPARgamma is involved in mesalazine-mediated induction of apoptosis and inhibition of cell growth in colon cancer cells. Carcinogenesis. 2008;29:1407-14.

[97] Feilchenfeldt J, Brundler MA, Soravia C, Totsch M, Meier CA. Peroxisome proliferatoractivated receptors (PPARs) and associated transcription factors in colon cancer: reduced expression of PPARgamma-coactivator 1 (PGC-1). Cancer Lett. 2004;203:25-33.

[98] Mukherji A, Kobiita A, Ye T, Chambon P. Homeostasis in intestinal epithelium is orchestrated by the circadian clock and microbiota cues transduced by TLRs. Cell. 2013;153:812-27. 


\section{FIGURE LEGEND}

Figure 1: A simplified overview of the cortisol and sex steroids synthesis pathway.

Glucocorticoids and sex steroids result from the conversion of cholesterol by cytochrome P450 enzymes as well as dehydrogenase enzymes (hydroxysteroid dehydrogenases; HSD). StAR protein is a transporter involved in the cholesterol transport to the mitochondria where the first, rate-limiting step catalyzed by P450scc occurs. In humans, cortisol can also result from the conversion of the metabolically inactive pro-hormone cortisone. In rodents, the first half of the synthesis pathway is conserved, except that rodents do not express the cyp17al gene in adrenals. Progesterone is transformed into 11-deoxycorticosterone (instead of 11deoxycortisol) and 11-deoxycorticosterone is transformed into corticosterone (instead of cortisol). Corticosterone can also results from the conversion of 11-dehydrocorticosterone (not represented). For each step, both the name of the protein and the corresponding gene are indicated, with the name of the gene in parenthesis. 
FIGURE 1

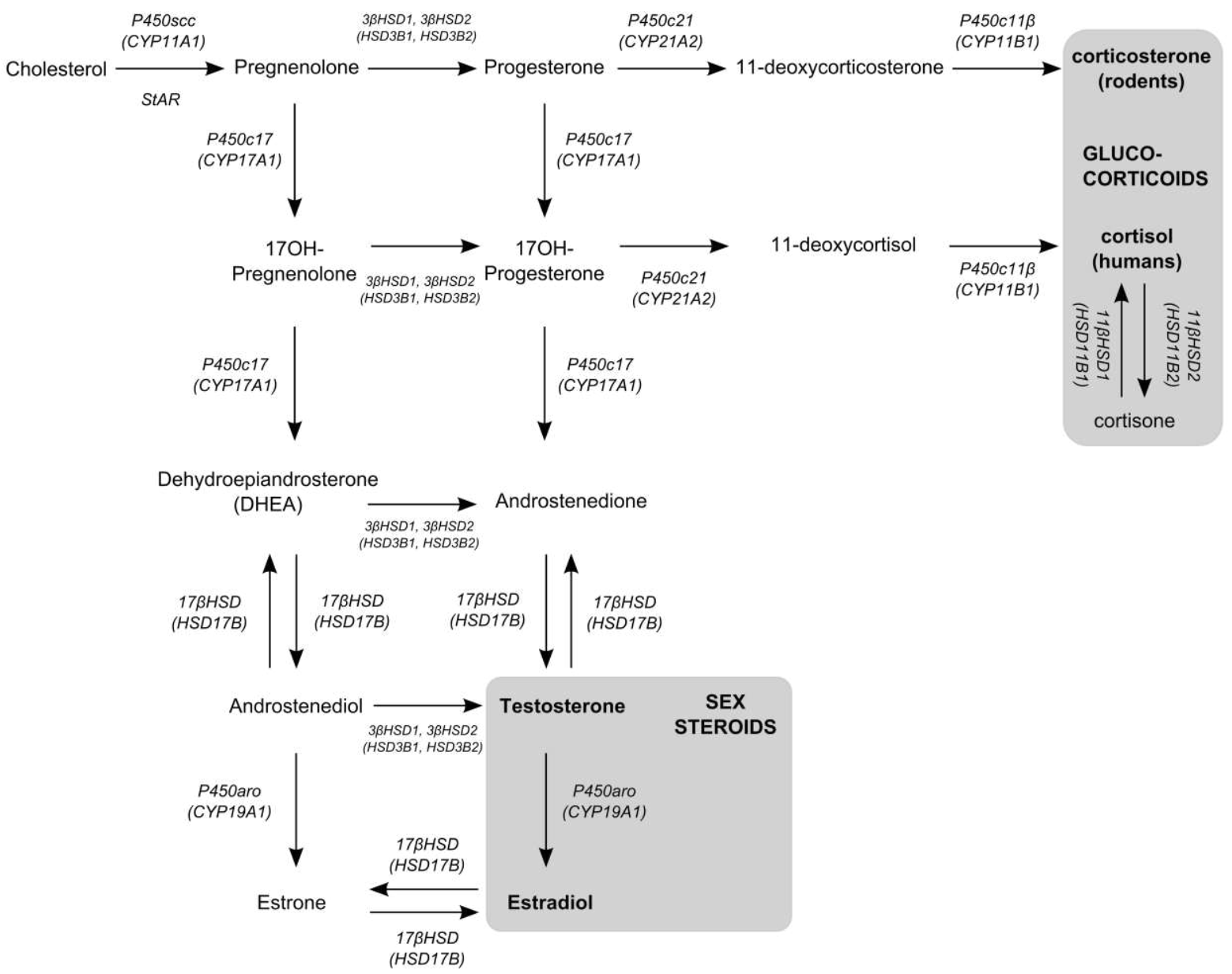

